\title{
IMPACT OF RESILIENCE ON STRESS AND RECOVERY IN ATHLETES
}

\author{
IMPACTO DA RESILLENNCIA NO ESTRESSE ENA RECUPERAÇÃO DE ATLETAS
}

ginal ARTICLE

IMPACTO DE LA RESILIENCIA EN LO ESTRÉS Y LA RECUPERACIÓN DE ATLETAS

Original Article

ARtigo Original

Artículo Original

Renan Codonhato

(Physical Education Professional)

João Ricardo Nickenig Vissoci²

(Psychology)

José Roberto Andrade do

Nascimento Junior ${ }^{3}$

(Physical Education Professional)

Marcus Vinícius Mizoguchi ${ }^{4}$

(Physical Education Professional)

Lenamar Fiorese ${ }^{1}$

(Physical Education Professional)

1. Universidade Estadual de Maringá, Department of Physical Education, Maringá, PR, Brazil. 2. Division of Emergency Medicine, Department of Surgery; Duke Global Neurosurgery and Neurology, Department of Neurosurgery, Duke School of Medicine. Duke Global Health Institute, Duke University. Durham, US.

3. Universidade Federal do Vale do São Francisco, Department of Physical Education, Petrolina, Brazil. 4. Universidade Federal de Mato Grosso, Department of Physical Education, Cuiabá, MT, Brazil.

\section{Correspondence:}

Physical Education Department, Universidade Estadual de Maringá. R. Pioneira Maria Ap. Araújo de Siqueira, 281, Bloco 01 Apt. 603, Bairro Sumaré, Maringá-PR, Brazil. 87035-614. gperenan@gmail.com

\begin{abstract}
Introduction: Resilience is a positive psychological characteristic that reflects an individual's capacity to better perceive, deal with, and overcome adversity; the sports environment is replete with adversities, which increase athletes' stress levels and may lead to undesirable outcomes. Objective: To analyze the impact of resilience levels on stress and recovery in athletes. Methods: Subjects were 150 athletes (aged 22.46 \pm 5.97 ) of both sexes (92 men and 58 women) who competed in the 2012 Paraná Open Games in different sports (107 in team and 43 in individual sports). Instruments were the Recovery-Stress Questionnaire (RESTQ-76 Sport) and a resilience questionnaire (CD-RISC-10). The following tests were used for data analysis: Kolmogorov-Smirnov normality test, Spearman Correlation Coefficient and Structural Equation Modelling (SEM). Results: The model significantly explained stress and recovery variability in $20 \%$ and $22 \%$, respectively; age-predicted resilience was 11\%; the model invariance test indicated a significant influence of sex and type of sport (multi-group analysis). Conclusion: Resilience plays an essential role in coping with and recovering from stress in competitive sports contexts, which is considered a determinant of success. Level of Evidence ll; Retrospective study.
\end{abstract}

Keywords: Psychological resilience; Psychological stress; Sport psychology.

\section{RESUMO}

Introdução: Resiliência éuma característica psicológica positiva que reflete a capacidade de um indivíduo melhor perceber, lidar e superar adversidades; o ambiente esportivo é repleto de adversidades que aumentam os níveis de estresse dos atletas, podendo levar a consequências indesejadas. Objetivo: Analisar o impacto dos níveis de resiliência no estresse e na recuperação de atletas. Métodos: Os participantes foram 150 atletas (22,46 $\pm 5,97$ anos) de ambos os sexos (92 homens e 58 mulheres), que competiram na fase final dos Jogos Abertos do Paraná 2012 de diferentes tipos de esporte (107 de modalidades coletivas e 43 de modalidades individuais). Os instrumentos usados foram o Questionário de Estresse e Recuperação (RESTQ-76 Sport) e um questionário de resiliência (CD-RISC 10). Para análise dos dados, foram usados os seguintes testes: de normalidade de Kolmogorov-Smirnov, Coeficiente de correlação de Spearman e Modelagem de Equações Estruturais (SEM). Resultados: O modelo explicou significativamente a variabilidade do estresse e recuperação em 20\% e 22\%, respectivamente; a resiliência foi prevista pela idade em 11\%; o teste de invariância do modelo indicou uma influência significativa do sexo e tipo de esporte (análise multigrupo). Conclusão: A resiliência tem um papel fundamental ao lidar e recuperar-se do estresse em contextos esportivos competitivos, o que é considerado um fator determinante do sucesso. Nível de Evidência Il; Estudo retrospectivo.

Descritores: Resiliência psicológica; Estresse psicológico; Psicologia do esporte.

\section{RESUMEN}

Introducción: Resiliencia es una característica psicológica positiva que refleja la capacidad de un individuo a percibir, enfrentary superar las adversidades; el ambiente deportivo es rico en adversidades, las que aumentan los niveles de estrés de los atletas, pudiendo llevar a consecuencias no deseadas. Objetivo: Analizar el impacto de los niveles de resiliencia en el estrés y recuperación de atletas. Métodos: Los sujetos estudiados fueron 150 atletas (22.46 \pm 5.97 años) que disputaron los Juegos Abiertos de Paraná 2012, de ambos sexos (92 hombres y 58 mujeres) y diferentes deportes (107 de deportes colectivos y 43 de deportes individuales). Los instrumentos utilizados fueron los Cuestionarios de Estrés y Recuperación (RESTQ-76 Sport) y un cuestionario de resiliencia (CD-RISC 10). Para el análisis de los datos fueron utilizados para los siguientes test: Kolmogorov-Smirnov, Coeficiente de Correlación de Spearman y Modelos de Ecuaciones Estructurales (SEM). Resultados: El modelo explicó significativamente la variación del estrés y recuperación en 20\% y 22\%, respectivamente; la resiliencia fue prevista por la edad en 11\%; el test de invariancia del modelo indicó una influencia significativa del sexo y tipo de deporte (análisis multigrupo). Conclusión: La resiliencia tiene un papel fundamental en el enfrentamiento y recuperación del estrés en contextos deportivos competitivos, lo que se considera un factor determinante para el éxito. Nivel de evidencia ll; Estudio retrospectivo.

Descriptores: Resiliencia Psicológica; Estrés Psicológico; Psicología del Deporte. 


\section{INTRODUCTION}

Facing challenging situations in a positive way may play an important role in avoiding recurrent stress-related problems in sports, a characteristic of resilient individuals. ${ }^{1}$ Resilience has gained importance as a way to improve one's psychological capacities for facing adverse situations, while potentially avoiding unwanted aspects of the stress process, like muscle stiffness, tension, and decreased attention and focus. ${ }^{2}$ Nevertheless, despite the increase in resilience-related literature, to the best of our knowledge, no study has yet analysed the resilience's role in coping and recovering from stress in athletes.

Resilience is the process of positive adaptation facing adverse situations in a specific context. ${ }^{3}$ Two key-points are shared by all resilience definitions: the existence of an adversity and positive adaptation. ${ }^{4}$ In order to better understand this process, the Conceptual Model of Sport Resilience ${ }^{2}$ was used as the theoretical framework for the present study. According to the model, an adverse situation will produce an agitation process in the athlete, characterized by unpleasant emotions and mental struggles. The agitation can have a positive outcome, improving this individual's psychological capacities and consequently benefiting future agitation processes.

Studies had shown that resilient athletes have lower anxiety levels, ${ }^{5}$ differences in coping strategies (facing and solving problems instead of avoiding them) as well as higher personal coping resources, ${ }^{6,7}$ and higher levels of self-concept and self-esteem ${ }^{8}$ compared to athletes with lower resilience levels. These individuals also presented a desirable self-regulation capacity ${ }^{9}$ and a positive correlation with psychological well-being. ${ }^{10}$ However, such studies investigated stress correlates, not the stress concept itself, which reinforces the need for evidences about the resilience impact over stress in sports.

The main studies investigating the resilience process in athletes adopted qualitative approaches, and seem to agree that resilience is essential for obtaining high sports performance at a high competitive level., ${ }^{911,12}$ Among the resilience literature, it was found only one study which quantitatively evaluated the direct positive impact that resilience exerts over stress in athletes, however, its main focus was to analyse individuals' mental health, and not sports-related specificities. ${ }^{10}$

In regards to the importance of this matter and the pointed literature gap, the present study had the objective to analyse the resilience levels' impact over stress and recovery in Brazilian athletes. Our main hypothesis is that resilience will have a positive effect in athletes' recovery, while negatively impacting their stress perception.

\section{METHODS}

Participants consisted of athletes participating in the 2012 Paraná Open Games finals, from different sports (swimming, cycling, chess, tennis, judo, football, futsal, handball and volleyball), which had placed among the Top 3 in the previous edition of this competition. Final sample was composed by 150 athletes (92 males and 58 females) with mean age of 22.46 \pm 5.97 years old, being 107 athletes from team sports and 43 from individual sports.

To identify the stress and recovery levels, the Brazilian version ${ }^{13}$ of the Recovery and Stress Questionnaire for Sports (RESTQ-76 Sport) was used. This instrument has 77 items in a 7-point Likert-type scale. Results are obtained in 10 stress subscales (general stress, emotional stress, social stress, conflicts/pressure, fatigue, lack of energy, physical complaints, disturbed breaks, emotional exhaustion and injury) and 09 recovery subscales (success, social recovery, physical recovery, general well-being, sleep quality, being in shape, personal accomplishment, self-efficacy and self-regulation). In the reliability analysis, Cronbach's al pha varied between 0.54 and 0.87 , with only three subscales (conflicts/pressure, success and physical recovery) presenting unwanted values $(a<0.70)$. This reliability result is similar to the scale validation study for the Brazilian sports context, which had also found alpha values lower than 0.70 for three dimensions (conflicts/pressure, success and personal accomplishment). Although unsatisfactory alpha values were obtained, these subscales were maintained, in order to evaluate its behaviour in the factorial analysis.

To verify athlete's resilience levels, the Brazilian version of 10-items Connor-Davidson Resilience Scale ${ }^{14}$ was used. This scale is composed of 10 items in a 5-point Likert-type scale. The result is a single-factor score varying from 0 to 40 points, with higher scores indicating higher resilience levels. Scale's reliability was $a=0.82$, indicating adequate data reliability.

The study was approved by the Ethics Committee in Human Research of the State University of Maringá (Opinion n³39/2011). Prior do data collection, the Paranás Sport Secretariat, coaches and athletes were contacted for approval. Subject's participation required reading and signing an Informed Consent Term.

\section{Data analysis}

Kolmogorov-Smirnov test was used for data distribution. Descriptive statistics were presented in median and interquartile range. For data correlation, Spearman Correlation Coefficient was used, with significance level at $p<0.05$.

Main analyses were conducted through Structural Equation Modelling (SEM), performed in the R software (v3.2) with lavaan package. The model intended to test our initial hypothesis that resilience has a direct influence over athletes' stress and recovery. Besides the resilience as an observed variable, two latent variables were theorized after the 19 subscales from RESTQ-76. Latent variables were composed by the questionnaire's respective subscales and named Stress and Recovery.

SEM was tested by the 2-Step method, verifying measurement variables' adequacy and models identification with latent variables before performing the structural equations. Step 1 - Confirmatory factor analysis of the measurement model and Step 2 - Identify and specify the structural model, stablishing paths for the latent variables. ${ }^{15}$ Confirmatory factor analysis of a two-factor measurement model was performed with 'stress' and 'recovery' as latent variables. ${ }^{16}$

Model adequacy was verified by the goodness of fit indicators and local adjustment was assessed by items' individual reliability and factor loadings. Square Mahalanobis distance $\left(D^{2}\right)$ was used to verify the existence of outliers, skewness (Sk) and kurtosis (Ku) were used to assess univariate data distribution, and Mardia coefficient to test data multivariate distribution (reference values: $|S k|<3.0$ and $|K u|<10.0) .{ }^{16}$ Due to a non-parametric distribution, model was estimated through WLSMV method. The consistency of model parameters was verified with bootstrapping technique ${ }^{15}$ defining a confidence interval for coefficients and parameters estimates.

Model fitness indicators were: $X^{2}$ (Chi-Square), $X^{2} / \mathrm{df}$ (Normalized Chi-Square with satisfactory values ranging between 1.0 and 3.0), RMSEA (Root mean square error of approximation < 0.08), GFI/AGFI (Goodness-of-fit index and Adjusted Goodness of fit index $>0.90$ ), CFI (Comparative fitness index $>0.90$ ), and TLI/NFI (Tucker-Lewis Index/Normalized fitness index $>0.90$ ). Paths were interpreted as $<0.20$ for small effect, $<0.49$ for medium effect, and $>0.50$ for large effect $(p<0.05) .{ }^{16}$ Model invariance was tested by Multi-group factor analysis, comparing the covariances and factor loadings for sex (male and female) and sport type (individual and team sport). Chi-square difference test was used for invariance significance between the model with fixed and free parameters. ${ }^{16}$ 


\section{RESULTS}

\section{Descriptive analysis and internal reliability}

Moderate resilience levels were found ( $M d=29.00 ; 24.00-34.00)$; along with low-stress/high-recovery profile (Figure 1). Regarding stress and recovery values, results indicated that either the athletes had ideal training and tapering strategies, or that this specific competition was not understood as important or challenging enough to substantially raise athletes' stress levels.

Inverse significant correlation was found between resilience and all ten stress subscales ( $r=-0.19$ to -0.41 ). It was also found that resilience positively correlated with eight out of nine recovery subscales $(r=0.22$ to 0.39 ), excluding only the physical recovery variable ( $p>0.05$ ), and highlighting self-regulation ( $r=0.39$ ) (Figure 2). Results were noticeably divided into two main dimensions: stress and recovery, suggesting the existence of two latent variables.

\section{Measurement model}

A two-factor model was tested as SEM's first step, checking for the relationships between the observed variables and their respective latent variables (stress and recovery). The model presented adequate fit $\left[X^{2}(151)=370.218 ; p=0.011 ; X^{2} / d f=2.45 ; C F I=0.96 ; G F I=0.99 ; T L I=0.95\right.$; $\mathrm{NFI}=0.93 ; \mathrm{RMSEA}=0.10$ (IC 95\% 0.08;0.13)], all variables had shown significant pathways, superior to 0.50 , confirming items' internal reliability. These results allowed the structural equation model testing.

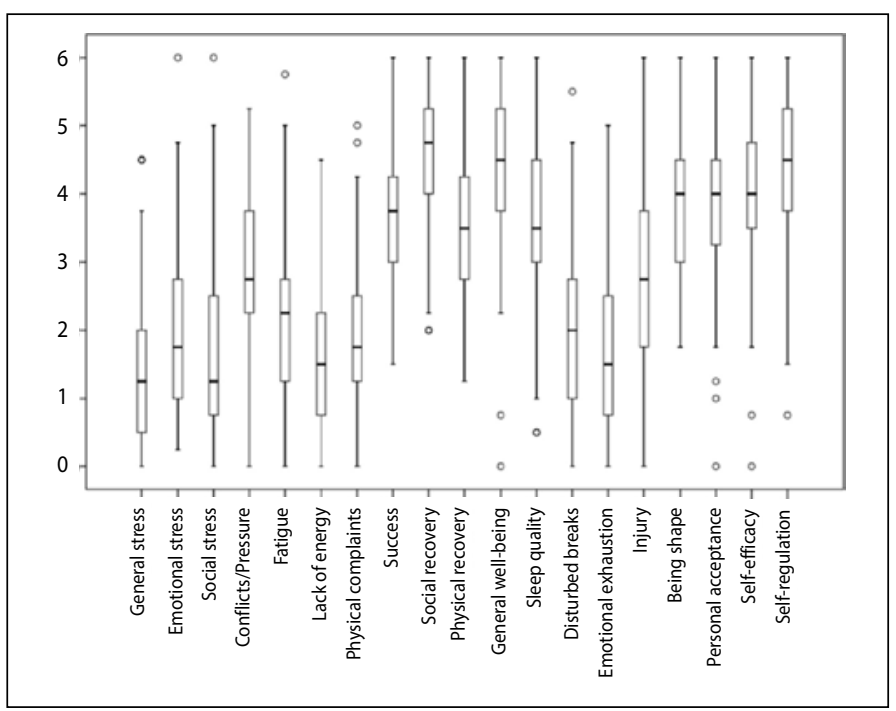

Figure 1. Sample's recovery and stress profile.

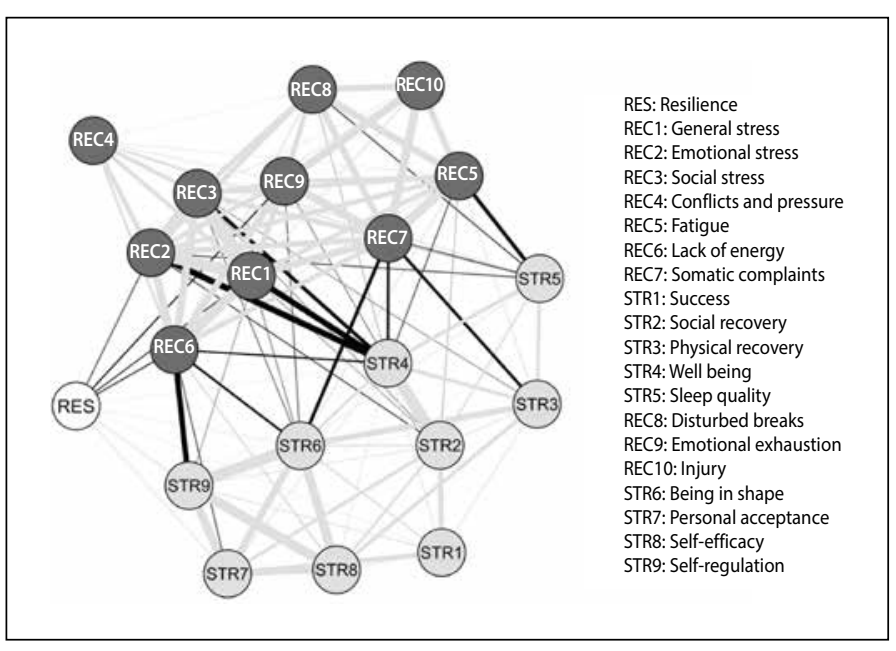

Figure 2. Correlation between resilience, stress and recovery in Brazilian athletes.

\section{Structural equation modelling (SEM)}

A single model was tested with direct pathways between recovery and stress, and between resilience and the two latent variables (Figure 3 ). The model had adequate fit $\left[X^{2}(187)=233.658 ; p=0.012 ; X^{2} / d f=1.25\right.$; $C F I=0.98 ; \mathrm{GFI}=0.99 ; \mathrm{TLI}=0.98 ; \mathrm{NFI}=0.93 ; \mathrm{RMSEA}=0.04(\mathrm{IC} 95 \% 0.02 ; 0.06)]$, and presented significant direct paths $(p<0.05)$.

Resilience was age-predicted $(r=0.33)$ and presented a positive impact on athletes' recovery $(r=0.48)$ and negative impact on their stress levels $(r=-0.46)$. Model explained stress and recovery variability in $21 \%$ and $23 \%$ respectively, supporting our initial study hypothesis. Moreover, resilience was age-predicted by $11 \%$.

Multi-group model analysis tested the model invariance for sex and sport type variables. For both cases, we observed that the invariance model with fixed factor loadings presented no distinction with the model with free parameters. Both models had adequate fitness indices with small differences between them. Comparing more restricted models, we observed that in models with fixed factor loadings and correlations, and even in a fourth model with fixed means between groups, there was a difference in chi-square and fit indicators values. Thus, we can accept that the model is influences by sex and sport type variables.

Analysing model's structure, no difference was found for both sex and sport type groups. However, factor loadings and explained variance (Table 1) were different between males (Stress=28\%, Recovery $=28 \%$ ) and females (Stress $=12 \%$, Recovery=16\%). Sport type also presented a difference in factor loadings and explained variance for resilience paths towards stress (Individual $=24 \%$, Team $=19 \%$ ) and recovery (Individual $=31 \%$, Team=19\%).

\section{DISCUSSION}

The present study aimed to investigate resilience's impact on stress and recovery of Brazilian athletes. Our results presented an important contribution to the understanding of the resilience's role in the sporting context, confirming our initial hypothesis that resilience negatively impacts stress, while positively impacting recovery. This suggests that psychological resilience has a relevant role in coping with stress and recovery for athletes, highlighting its importance in the understanding of these variables.

Our present finds are consistent with the adopted theoretical framework. ${ }^{2}$ According to the theory, resilience is a complex process encompassing adversity, agitation and positive outcomes. Therefore, by reducing the perception of stress and positively affecting recovery resilience will benefit the agitation process, leading to improved ability to deal with context adversities. Moreover, resilience will also facilitate positive outcomes in the face of stress, giving a positive feedback to personal resources that will strengthen the athlete to face future adversities. Thus, we expect resilient athletes to have a more adaptive response to stress.

Our present findings also agree with recent literature, that, although having different study designs in its majority, have being heading towards the same idea that resilience is potentially related to a more adaptive stress process. ${ }^{49-11,17}$ Athletes are constantly exposed to a wide diversity of stressors, from daily personal problems to specific sport-related struggles, however, resilient individuals might deal with such demands in a different way, highly successful athletes (and also very resilient) evaluate these demands as growth opportunities, challenges to be overcome."11

Another important result refers to the inverse correlations between resilience and both emotional exhaustion and lack of energy, indicating lower burnout and struggle to focus/make decisions. ${ }^{18}$ In other words, due to the way resilient individuals face their problems, it is more likely for them to show lower psychological exhaustion, having a smaller impact in their decision making capacity. 


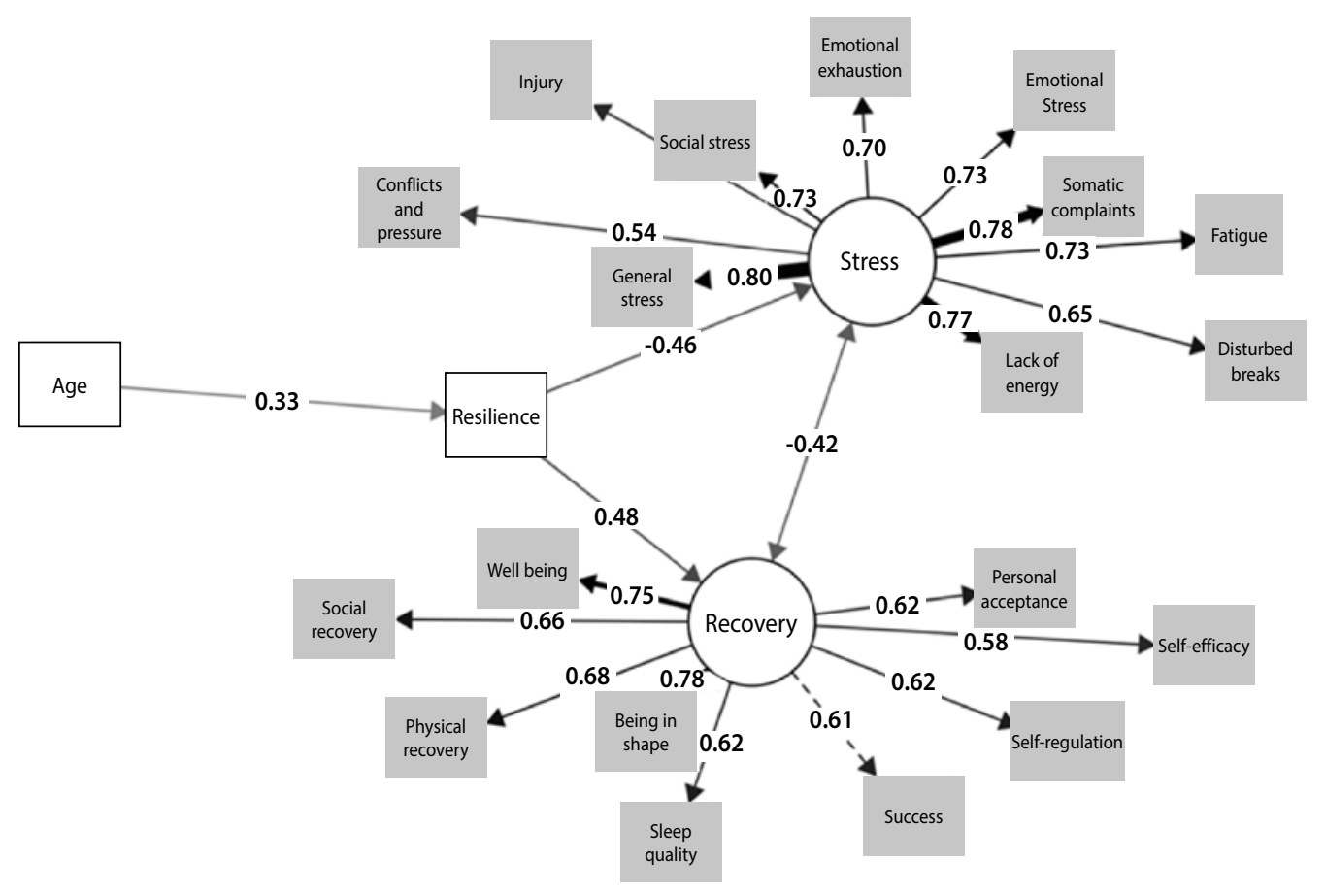

Figure 3. Resilience, stress and recovery model.

Table 1. Model's invariance analysis as a function of sex and type of sport.

\begin{tabular}{c|c|c|c|c}
\hline Groups & \multicolumn{2}{|c|}{ Stress } & \multicolumn{2}{c}{ Recovery } \\
\hline & $\boldsymbol{\beta}$ & $\mathbf{r}^{\mathbf{2}}$ & $\boldsymbol{\beta}$ & $\mathbf{r}^{\mathbf{2}}$ \\
\hline Sex & & & & \\
\hline Male (1) & -0.53 & 0.28 & 0.53 & 0.28 \\
\hline Female (2) & -0.35 & 0.12 & 0.40 & 0.16 \\
\hline Sport type & & & & \\
\hline Individual (1) & -0.49 & 0.24 & 0.56 & 0.31 \\
\hline Team (2) & -0.44 & 0.19 & 0.44 & 0.19 \\
\hline
\end{tabular}

Note: All pathways were statistically significant

To the best of our knowledge, the present study is the first to quantitatively study athletes' recovery-related aspects facing stress. Resilience has presented positive relationship with recovery in general, and more specifically with self-regulation and personal accomplishment, indicating that resilient individuals are able to make better use of their psychological skills to prepare, motivate and establish goals for themselves, having fun with their sport, and feeling integrated with their teams. ${ }^{18}$ Brown et al. ${ }^{9}$ had found similar results: internal focus, focus on long-term aims, staying motivated and committed, making goals and believing in themselves as cognitive strategies/characteristics of resilient athletes.

Age's influence on resilience is consistent with resilience concept itself, having in mind that building up resilience is a process that happens over time based on one's experiences throughout life, ${ }^{4}$ it is expected that older and more experienced individuals would have faced a greater number of adversities, and in different contexts of life, possibly increasing their resilience levels. However, more studies are necessary in other to properly address how age and time of sport practice affect resilience.

Although there is a consistency in the predictive relationships between models (general, sex and sport type), the explained variance had varied, indicating that resilience impacts stress and recovery levels in different intensities based on sex and sport type. It is supposed that there are differences in personality between males and females, and individual and team sport athletes, however, no resilience studies were found to address this matter, precluding further inferences. This is a unique contribution of our study, being the first to report possible differences in resilience's role as a function of athletes' sex and sport type.

Despite the contributions, some limitations have to be mentioned. The state-level competition may not have exposed athletes to the same demands as national/international competitions, which could have explained the reported low levels of stress, limiting the understanding of resilience in a high-stress situation. This might also limit the results generalizability to other competitive levels, according to Luthar et al., ${ }^{3}$ resilience has to be investigated in the specific context on which it manifests. However, it is worth to mention that most athletes play at a state level, for only a small fraction of them will reach the elite level, making our results applicable to the majority of athletes.

In order to comprehend the present constructs in a general sport context, our study had a heterogenic sample (individual and team sports, with different levels of physical contact). Although resilience and stress processes are common to all sports, a wide sample can be both a strong aspect and a limiting factor, due to the fact that each sport type will have a smaller representativity, hindering the understanding of more specific aspects of each sport.

Future investigations should increase sample size and include a design that allows testing each sport type. It is also recommended that new studies seek to understand the resilience role in recovering and coping with stress from sports initiation to the elite levels. Lastly, we suggest a new gap to be investigated, regarding the differences that resilience presented based on sex and sport type.

\section{CONCLUSION}

Resilience is a factor that positively interferes in athletes' stress/ recovery process. Thus, resilience can be considered an essential characteristic for athletes to deal and overcome demands in competitive sports. We suggest resilience to be taken in consideration for coaches and sports psychologists, in order to better manage demands/pressure 
and support over each individual, challenging and stimulating athletes according to their capacities.

Professionals working with different sports should consider looking into their athletes' resilience levels, identifying those with higher vulnerability, and applying proper psychological interventions to strengthen resilience levels. In the other hand, an investment in detecting and training highly resilient children could be considered, as this aspect seems to play an essential role in being successful in a sports career.

\section{ACKNOWLEDGMENT}

This work was support by the Brazilian Government Agency CAPES (English name: Coordination for the Improvement of Higher Education Personnel; Portuguese: Coordenação de Aperfeiçoamento de Pessoal de Nível Superior).

All authors declare no potential conflict of interest related to this article.

AUTHORS' CONTRIBUTIONS: Each author made significant individual contributions to this manuscript. RC (0000-0003-1061-7111)* article conception, data gathering, interpretation of results, writing of the manuscript; JRNV (0000-0001-7276-0402)* data analysis, data interpretation, critical review of the manuscript. JRANJ (0000-0003-3836$6967)^{*}$ data gathering, data analysis, critical review of the manuscript; MVM (0000-0002-7680-4393)* data gathering, writing of the manuscript, critical review of the manuscript; LF(0000-0003-1610-7534)* article conception, critical review of the manuscript, approval of the final version. *ORCID (Open Researcher and Contributor ID).

\section{REFERENCES}

1. Fletcher D, Fletcher J. A meta-model of stress, emotions and performance: Conceptual foundations, theoretical framework, and research directions [Abstract]. J Sports Sci. 2005;23:157-8.

2. Galli N, Vealey RS." "Bouncing Back"from Adversity: Athletes'Experiences of Resilience. The Sport Psychologist. 2008;22(3):316-35

3. Luthar SS, Cicchetti D, Becker B. The Construct of Resilience: A Critical Evaluation and Guidelines for Future Work. Child Dev. 2000;71(3):543-62

4. Fletcher D, Sarkar M. Psychological resilience a review and critique of definitions, concepts, and theory. Eur Psychol. 2013;18(1):12-23.

5. Martin-Krumm CP, Sarrazin PG, Petersonc C, Famose J. Explanatory style and resilience after sports failure Pers Individ Dif. 2003;35(7):1685-95.

6. Belém IC, Caruzzo NM, Nascimento Júnior JRA, Vieira JLL, Vieira LF. Impact of coping strategies on resilience of elite beach volleyball athletes. Rev Bras Cineantropom Desempenho Hum. 2015;16(4):447-55.

7. Yi JP, Smith RE, Vitaliano PP. Stress-Resilience, IIIness, and Coping: A person-focused investigation of young women athletes. J Behav Med. 2005;28(3):257-65.

8. Mummery WK, Schofield G, Perry C. Bouncing back: The Role of coping style, social support and self-concept in resilience of sport performance. Athletic Insight. 2004;6(3):1-18.

9. Brown $\mathrm{HE}$, Lafferty ME, Triggs $\mathrm{C}$. In the face of adversity: resiliency in winter sport athletes. Sci Sports. 2015;30(5):105-17.
10. Nezhad MAS, Besharat MAB. Relations of resilience and hardiness with sport achievement and menta health in a sample of athletes. Procedia Social and Behavioral Sciences. 2010;5:457-97.

11. Fletcher D, Sarkar M. A grounded theory of psychological resilience in Olympic champions. Psychol Sport Exerc. 2012;13(5):669-78.

12. Morgan PBC, Fletcher D, Sarkar M. Defining and characterizing team resilience in elite sport. Psychol Sport Exerc. 2013;14(4):549-59.

13. Costa LOP, Samulski DM. Processo de validação do questionário de estresse e recuperação para atletas (RESTQ-Sport) na língua portuguesa. Rev Bras Ci e Mov. 2005;13(1):79-86.

14. Lopes VR, Martins MCF.Validação Fatorial da Escala de Resiliência de Connor-Davidson (Cd-Risc-10) para Brasileiros. Rev Psicol Organ Trab. 2011;11(2):36-50.

15. Marôco J. Análise de equações estruturais: Fundamentos teóricos, software \& aplicações. Pêro Pinheiro, Portugal: Report Number, Lda; 2010.

16. Kline RB. Principles and practice of structural equation modeling. New York: Guilford press; 2012.

17. Bejan R, Tonita F. The role of resilience in coping with stress in sports. Procedia - Social and Behavioral Sciences. 2014;117:402-7.

18. Kellmann M, Kallus KW. The Recovery-Stress Questionnaire for Athletes; user manual. Champaign, IL: Human Kinetics; 2001 